\title{
Association Between Intimate Partner Violence During Pregnancy And Birth Asphyxia In Hospitals Of Tigray Region, Ethiopia
}

\section{Kahsay Gebreslasie ( $\nabla$ kahsay14z@gmail.com )}

Mekelle University College of Health Sciences

Gelawdiwos Gebre

Mekelle University

Dawit Zenebe

Mekelle University

Solomon Weldemariam

Mekelle University

Mehret Ab Mehari

Mekelle University College of Health Sciences

Rahel Nardos

Oregon Health \& Science University Casey Eye Institute

Akilil Birhanne

Mekelle University

\section{Research}

Keywords: Intimate partner, violence, pregnancy, birth asphyxia, association

Posted Date: August 24th, 2020

DOI: https://doi.org/10.21203/rs.3.rs-58682/v1

License: (9) (i) This work is licensed under a Creative Commons Attribution 4.0 International License. Read Full License 


\section{Abstract}

Background: Birth asphyxia is the main causes of neonatal mortality and morbidity worldwide. Some studies indicate intimate partner violence during pregnancy is a risk factor for birth asphyxia. In Ethiopia, intimate partner violence is reported in nearly 26 percent of pregnancies. Despite this high prevalence, there is lack of data about the association of birth asphyxia and intimate partner violence. The aim of this study was to assess the prevalence of intimate partner violence during pregnancy and its associated factors with birth asphyxia in health facilities in the Tigray region of northern Ethiopia.

Methods: This was an institutional based cross-sectional study conducted at select health facilities in the Tigray region of Ethiopia. Random sampling technique was employed to select health facilities and systematic sampling was used to select the study participants. Data was entered by using Epi info version 3.5.1 and was analyzed using SPSS version 20. Bivariate and multivariate analysis was done to assess the association between exposure to intimate partner violence during pregnancy and birth asphyxia after adjusting for possible confounders.

Results: The prevalence of intimate partner violence during pregnancy was $7.3 \%$. Eighty two $(12.7 \%)$ babies were delivered with birth asphyxia. Intimate partner violence during pregnancy had significant association with birth asphyxia AOR $(95 \% \mathrm{Cl})=4.4(2-9.8)$. In addition to this residence, AOR $(95 \% \mathrm{Cl})$ $=2.7(1.55-4.8)$, age $>19, \mathrm{AOR}(95 \% \mathrm{Cl})=2.9(1.29-6.5)$, age 20-35, AOR $(95 \% \mathrm{Cl})=3.1(1.06-9.3)$, gestational age $<37$ weeks, $\mathrm{AOR}(95 \% \mathrm{Cl})=7.2(3.5-14.8)$ and low birth weight, $\mathrm{AOR}(95 \% \mathrm{Cl})=3.9(2.1-7.3)$ had significant association with birth asphyxia.

Conclusions: The prevalence of birth asphyxia in this study is high. Women who experienced intimate partner violence during pregnancy increased the risk of birth asphyxia.

\section{Background}

Intimate partner violence (IPV) is among the most common violence against women and it is a public health and human right issue[1,2]. Report from across ten countries $15 \%-71 \%$ of women experience a physical or sexual or both types of violence in their lifetime[3]. The occurrence of IPV among pregnant mothers range from $2 \%$ in Australia to $13.5 \%$ in Uganda [4]. A systematic review from African countries showed that, IPV during pregnancy ranged from $2 \%$ to $57 \%[5]$. Other researches also showed that IPV during pregnancy has negative impact on the health of the mothers' and their children [2].

Apgar score, a means evaluating of the newborn baby's physical condition immediately after birth, is low in apgar score/ asphyxiated baby is highly correlated with neonatal mortality [6]. Birth asphyxiated babies had 34.5 times higher risk of mortality compared to non-birth asphyxiated babies[7]. According to the WHO, there were 20 stillbirths 1000 per birth and 51 neonatal mortality rate per 1000 live birth [8]. The survey also indicated that neonatal mortality was 95 per 1000 live births [9]. 
Studies show that, birth asphyxia is related to severe disability such as low cognitive function, neurological problem and subtle cognitive impairment $[9,10]$. Although some studies demonstrated an association between IPV during pregnancy and birth asphyxia [11], others reported no association [12]. The differences in findings might be due to regional variability and underreporting of IPV. In Ethiopia, especially in the Tigray region, there is little if any research done to investigate the association between IPV during pregnancy and birth asphyxia.

Although Ethiopia has formulated different policies to avert the rate of neonatal mortality and morbidity, it still remains unacceptably high. Given the high prevalence of IPV in Ethiopia, it is critical to understand the potential role of IPV on the high rate of neonatal mortality and morbidity. Given that IPV is potentially amenable to intervention, this research will inform policy makers and health professionals and can have important implications on neonatal outcomes.

\section{Methods}

\section{Study setting}

To execute this research, institutional based cross-sectional study was used. The study was conducted from October 2017 to June 2018 among women who gave birth in Tigray Regional hospitals. Tigray region is located $783 \mathrm{~km}$ from Addis Ababa, capital city of Ethiopia. Based on the 2007 census, the population was estimated to be $4,316,988$. Women of child bearing age (15-49) comprise 251,650 of the population. According to 2015 Tigray Regional Health Bureau annual report there were a total of, one specialized hospital, 15 general hospitals, 22 primary hospitals, 204 health centers and 712 health posts that were federally run. There were also three private hospitals. According to Mini EDHS 2019, 48\% of women gave birth at health facility (13).

\section{Study Participants}

To execute this research, institutional based cross-sectional study was used. Women who gave birth in selected hospitals of Tigray region and who were present during data collection time were included in the study. Babies with visible congenital anomalies were excluded from the study.

To calculate the sample size, we used available data that indicates 25.8 percent prevalence of IPV during pregnancy in Ethiopia [14] and 95\% confidence interval, 5\%margin of error, design effect 2 and expected non response rate $10 \%$. Based on this the calculated sample size was 648 . There are 41 hospitals ( 1 specialized hospital, 15 general hospitals, 22 primary hospitals and 3 private hospitals) which provide delivery service in the study area; health facilities were stratified into private and public hospitals. For this study, one private hospital and eight public hospitals were selected by simple random sampling technique. Participants from each health facility were selected by systematic sampling. Every 3rd postpartum woman was included until the required sample size was reached. If the selected participant was not eligible, then the next participant was included. The average client load for each facility during the 3 months preceding data collection was used as basis for proportional allocation to each health facility and to find the interval. 


\section{Data Collection Tools}

A questionnaire were prepared first in English and then translated into Tigrigna and again back translated to English by native language experts to keep the consistency of the questionnaires. Data on maternal socioeconomic status, IPV obstetrics factors was collected during discharge time by trained interviewers using pretested questionnaires. Low birth weight was assigned if the neonate weighed $<2500 \mathrm{~g}$, and preterm birth was assigned if the neonate was born at $<37$ completed weeks of gestation but $>28$ weeks.

To maintain data accuracy of birth asphyxia: Evaluated by trained data collectors and senior midwifes using standardization tool stared from onset of labor and ended after five minute of postpartum. Birth asphyxia was evaluated by considering apgar score. Apgar score assessed by using five variables. 1) Breathing effort: regular breathing score 2; irregular breathing and less than 30 breath/minute score 1; non 0.2 ) Regularity of heart rate: 100 beat/minute or more score 2; less than 100 beat/minute score 1 ; none score 0.3 ) Movement and muscle tone: active score 2; moderate score 1; limp score 0. 4) Skin color: pink score 2; bluish extremist score 1; totally bluish 0.5 ) reflex response to stimuli: crying score 2; whimpering score 1 ; silence 0 . All values was summed by investigator and values below seven considered as having birth asphyxia [15].

To measure IPV during pregnancy, participants were asked if they have a history of physical violence during pregnancy such as being slapped, pushed or shoved, hit with the fist or something else that could hurt her, beaten on her abdomen, choked or burnt on purpose, or been attacked or threatened by knife, gun or other weapons. Participants were also asked about history of emotional violence during pregnancy such as being insulted, humiliated, intimidated on purpose, and threatened. Sexual violence was defined as being forced to have sexual intercourse without consent, complying to have sexual intercourse due to fear, being forced to do something sexual that she found degrading or humiliating. If a participant was found to have been exposed to one or more of the above violence types, she was identified as having been exposed to IPV during pregnancy.

The data was collected by nine midwives (diploma level training) and supervised by four midwives (bachelor level training).To maintain data quality, the questionnaire was pretested on $10 \%$ of the total sample size. Training was given for both data collectors and supervisors about the aim of the study, procedures, and how to approach the study participants and data collection techniques. Data was checked daily by the supervisors and investigators for completeness. Since IPV is a very sensitive issue for participants, interviews were made in a private room to maintain confidentiality of the interviewees and to encourage them to speak-up.I

\section{Statistical analysis}

Double data entry was done using EPI Info version 3.4.1, 2008 and data was exported to SPSS version 20 software package for analysis. Experience of any physical, sexual or emotional violence was considered if a woman reported being exposed to at least one of the acts of violence exerted by her partner when she was pregnant with the current neonate. 
To determine the association between maternal exposure to intimate partner violence and birth asphyxia, logistic regression analyses were done, and odds ratios with 95\% confidence intervals were calculated. Multivariable logistic regression analysis was performed where intimate partner violence plus other variables that could affect newborn were included. The degree of association between independent and dependent variables were assessed using odds ratio with $95 \%$ confidence interval and significant association was considered at $P$ value of $<0.05$.

\section{Results}

\section{Socio-demographic and behavioral characteristics}

A total of 647 participants took part in this study with a response rate of $99.8 \%$. Out of the total respondents, $458(70.78 \%)$ were urban residents. The mean age of the respondents was $27 \pm 6$ years. Majority of the respondents $530(81.9 \%)$ were between ages $20-35$ years old. Of the total participants, 610(94.28\%) were married and 301 (46.5\%) were housewives (Table 1). 
Table 1

Socio-Demographic characteristics of respondents, Tigray, North, Ethiopia, 2018

\begin{tabular}{|c|c|c|c|}
\hline \multicolumn{2}{|l|}{ Variable } & \multirow{2}{*}{$\begin{array}{l}\text { Frequency } \\
458\end{array}$} & \multirow{2}{*}{$\begin{array}{l}\text { Percent } \\
70.78\end{array}$} \\
\hline Residence & Urban & & \\
\hline & Rural & 189 & 29.22 \\
\hline \multirow[t]{3}{*}{ Age } & $\leq 19$ & 50 & 7.7 \\
\hline & $20-34$ & 530 & 82 \\
\hline & $\geq 35$ & 67 & 10.3 \\
\hline \multirow[t]{2}{*}{ Religion } & Orthodox & 581 & 89.8 \\
\hline & Muslim & 66 & 10.2 \\
\hline \multirow[t]{5}{*}{ Educational Status } & Unable to read \&write & 108 & 16.7 \\
\hline & Read and write & 44 & 6.8 \\
\hline & Primary education & 175 & 27 \\
\hline & Secondary education and college & 211 & 32.6 \\
\hline & Diploma and above & 109 & 16.8 \\
\hline \multirow[t]{2}{*}{ Marital Status } & Married & 610 & 94.3 \\
\hline & Single & 37 & 5.7 \\
\hline \multirow[t]{6}{*}{ Occupational status } & Housewife & 301 & 46.5 \\
\hline & Merchant & 71 & 11 \\
\hline & Farmer & 127 & 19.6 \\
\hline & Private employee & 42 & 6.5 \\
\hline & Governmental employee & 95 & 14.7 \\
\hline & Others & 11 & 1.7 \\
\hline
\end{tabular}


Table 2

Obstetrics characteristics of respondents, Tigray, North,

Ethiopia, 2018

\begin{tabular}{|llll|}
\hline Variable & & Frequency & Percentage \\
\hline Mode of delivery & Vaginal & 492 & 76 \\
\cline { 2 - 4 } PROM & C/S & 155 & 24 \\
& Yes & 162 & 25 \\
\cline { 2 - 4 } Hypertension & No & 485 & 75 \\
\hline APH & Yes & 66 & 10.2 \\
\cline { 2 - 4 } & No & 581 & 89.8 \\
\hline ANC follow up & Yes & 35 & 5.4 \\
\cline { 2 - 4 } & No & 612 & 94.6 \\
\hline Pregnancy wanted & Yes & 611 & 94.4 \\
\cline { 2 - 4 } & No & 36 & 5.6 \\
\hline Preterm delivery & Yes & 70 & 93.5 \\
\cline { 2 - 4 } & No & 577 & 89.2 \\
\hline Low birth weight & Yes & 120 & 18.5 \\
\cline { 2 - 4 } & No & 527 & 81.5 \\
\cline { 2 - 4 } & & & 10.8 \\
\hline
\end{tabular}

From the total participants $47(7.3 \%)$ experienced intimate partner violence during their most recent pregnancy. Of these, $22(46.8 \%)$ experienced physical violence, $8(17 \%)$ psychological violence, $39(60 \%)$ sexual violence.

\section{Association between intimate partner violence during pregnancy and birth asphyxia}

On multivariate analysis, there was significant association between intimate partner violence during pregnancy and birth asphyxia. Women who experienced in intimate partner violence during pregnancy have 4.4 times increased risk of birth asphyxia compared to their counterparts (AOR $(95 \% \mathrm{Cl})=4.4(2-9.8)$. Other factors that were associated with birth asphyxia include rural residence, younger age at pregnancy, gestational age less than 37 week and neonatal low birth weight. Women from rural areas have 2.7 times increased of risk of birth asphyxia as compared to women from urban areas (AOR $=2.7(95 \% \mathrm{Cl}, 1.55-4.8)$. Women who are $<19$ year old have 2.9 times increased risk of birth asphyxia as compared to women who 
are 35 years old $(\mathrm{AOR}=2.9(95 \% \mathrm{Cl}, 1.29-6.5)$. Women with ages between $20-35$ have 3.1 times increased risk of birth asphyxia as compared to women with ages greater than $35(\mathrm{AOR}=3.1(95 \% \mathrm{Cl}, 1.06-9.3)$. In the same way gestational age less 37 weeks have 7.2 times increased risk of birth asphyxia (AOR = 7.2(95Cl,3.5-14.8)and low birth weight have 3.9 time increased risk of birth asphyxia as compared to counterpart $(\mathrm{AOR}=3.9(95 \% \mathrm{Cl}, 2.1-7.3)($ Table 3$)$. 
Table 3

Bivariate and multivariable logistic regression analyses of birth asphyxia by socio demographic variables, health-related variables, and intimate partner violence during pregnancy

\begin{tabular}{|c|c|c|c|c|c|}
\hline \multirow[t]{2}{*}{ Variables } & & \multicolumn{2}{|c|}{ Birth asphyxia } & \multirow[t]{2}{*}{$\operatorname{COR}(95 \% \mathrm{Cl})$} & \multirow[t]{2}{*}{$\operatorname{AOR}(95 \% \mathrm{Cl})$} \\
\hline & & Yes & No & & \\
\hline \multirow[t]{2}{*}{ Marital status } & Marriage & 77 & 533 & 1:00 & \\
\hline & Single & 5 & 32 & $1.08(0.4-2.8)$ & \\
\hline \multirow[t]{2}{*}{ Resident } & Urban & 41 & 417 & $1: 00$ & $1: 00$ \\
\hline & Rural & 41 & 148 & $2.8(1.75-4.5)$ & $2.7(1.55-4.8)$ \\
\hline \multirow[t]{2}{*}{ Religion } & Orthodox & 74 & 507 & $1: 00$ & \\
\hline & Muslim & 8 & 58 & $.94(.43-2)$ & \\
\hline \multirow[t]{3}{*}{ Age } & $<19$ & 13 & 37 & $2.8(1.4-5.5)$ & $2.9(1.29-6.5)$ \\
\hline & $20-35$ & 59 & 471 & $2(.79-5)$ & $3.1(1.06-9.3)$ \\
\hline & $>35$ & 10 & 57 & $1: 00$ & $1: 00$ \\
\hline \multirow[t]{2}{*}{ IPV } & Yes & 15 & 32 & $3.7(1.9-7.24)$ & $4.4(2-9.8)$ \\
\hline & No & 67 & 533 & $1: 00$ & $1: 00$ \\
\hline \multirow[t]{2}{*}{ Hypertension } & Yes & 10 & 56 & $1: 00$ & \\
\hline & No & 72 & 509 & $.79(.38-1.6)$ & \\
\hline \multirow[t]{2}{*}{$\mathrm{APH}$} & Yes & 8 & 27 & $1: 00$ & \\
\hline & No & 74 & 538 & $.46(.2-1.06)$ & \\
\hline \multirow[t]{2}{*}{ Habit of alcohol intake } & Never & 44 & 315 & $1: 00$ & \\
\hline & Sometimes & 38 & 250 & $1.08(.68-1.7)$ & \\
\hline \multirow[t]{2}{*}{ Pregnancy wanted } & Yes & 76 & 529 & $1: 00$ & \\
\hline & No & 6 & 36 & $1.16(.47-2.8)$ & \\
\hline \multirow[t]{2}{*}{ ANC follow up } & Yes & 74 & 537 & $1: 00$ & \\
\hline & No & 8 & 28 & $2(.91-4.7)$ & \\
\hline \multirow[t]{2}{*}{ Mode of delivery } & Vaginal & 64 & 428 & $1.1(.65-1.98)$ & \\
\hline & Cesarean delivery & 18 & 137 & 1:00 & \\
\hline \multirow[t]{2}{*}{ Gestational age } & $<37$ week & 35 & 35 & $11.2(6.4-19.6)$ & $7.2(3.5-14.8)$ \\
\hline & >=37 week & 47 & 530 & 1:00 & \\
\hline
\end{tabular}




\begin{tabular}{|llllll|}
\hline Low birth weight & Yes & 45 & 75 & $7.9(4.8-13)$ & $3.9(2.1-7.3)$ \\
\cline { 2 - 6 } & No & 37 & 490 & $1: 00$ & $1: 00$ \\
\hline
\end{tabular}

\section{Discussion}

This study which assessed the association between IPV during pregnancy and birth asphyxia provided new and important information that has been missing from research in low income countries like Ethiopia. The magnitude of intimate partner violence during pregnancy is concerning and can have important implications on neonatal outcome. In this study, the prevalence was $7.3 \%$. This is in line with the report from WHO 8\% of Ethiopian women experienced physical violence during pregnancy [16]. But it is lower than studies done in Tanzania (30\%), Vietnam (32.5\%), Ethiopia hosanna (23\%) and southeast Ethiopia $(25.8 \%)[17,18,12,14]$. The differences are likely partly due to true variations in prevalence, but could also be due to differences in study methodologies, timing of study and under reporting of IPV. In Ethiopia for example, the two studies done in Hosanna and southeast Ethiopia might due to changes in partner violence awareness between 2013 and 2014 and the study area difference may also other reason, husband in northern part of Ethiopia are more educated and can understand the disadvantage of violence.

In our study, the prevalence of birth asphyxia was $12.7 \%$. A study done in the University of Gondar's Hospital and in Jimma zone public hospital found similar findings where in the proportion of birth asphyxia were $13.8 \%$ and $12.5 \%$ respectively $[15,19]$. This study result is higher than in the study done in Dilchora Referral Hospital, in Dire Dawa city administration where the magnitude of birth asphyxia was $3.1 \%[20]$. The difference might be due to differences in risk factors, study area characteristics and the limitations intrinsic to retrospective data collection.

Our study found that IPV during pregnancy is significantly associated with asphyxia. This finding is in line with a research done among women in Massachusetts who were abused during pregnancy, and found to have increased the risk of birth asphyxia as compared to those women not exposed to abuse during pregnancy [11]. Women who are exposed to IPV may experience more hypertension and reduced blood flow and oxygen to the fetus during labor [21]. Furthermore, IPV may predispose women to higher psychological or emotional distress which in turn may lead to fetal distress.

In this study birth asphyxia has association with residence, women's age, gestational age and low birth weight. Women who come from rural areas have 2.7 times the risk birth asphyxia as compared to women from urban areas. This may be due to delayed access to timely obstetric care that disproportionately impacts women from rural areas compared to women from urban areas.

In our study, women who delivered before 37 weeks had about seven times higher risk of birth asphyxia compared to women with term pregnancies. This finding is similar to research done in Rajavithi Hospital- 
Thailand where women gave birth before 37 weeks had a higher risk of birth asphyxia among their babies [22]. Similarly another research done in Grady Memorial Hospital, Atlanta, Georgia showed that women who delivered before 37 weeks had increased risk of birth asphyxia [23]. This is not surprising as babies born preterm have immature respiratory systems that predispose them to birth asphyxia. Similarly, our findings show that babies born with low

Birth weight has four times increased risk of birth asphyxia compared to normal weight babies. This finding is supported by multiple other studies including ones done in Gondar university hospital and Jimma zone public hospitals in Ethiopia $[15,19]$. The pathophysiology for this is likely similar to that of preterm babies in which the respiratory systems are not fully developed $[15,19]$.

The current study also revealed that women whose age is less than 35 years old were about 3 times more likely to have birth asphyxia compared to those women whose age greater than 35 years old. This finding is supported by research conducted in Dilchora Referral Hospital, in Dire Dawa 'where women's age less than 25 years were risk factors for birth asphyxia [20]. This might be due to the fact that most women greater than 35 years old are multipara with shorter duration of labor thus reducing the risk of birth asphyxia.

\section{Strength Of The Study}

The strength of this study is that it is a large prospective well sampled cross-sectional study that includes both rural and urban participants. It is also the first study to look at the association between IPV and birth asphyxia in the Tigray region of Ethiopia.

\section{Limitation Of The Study}

The limitation of this study is that because of the design of the study, we cannot determine direct causal relationships and this study not assessed intra partum factors that affect birth outcome.

\section{Conclusion}

This study showed that the incidence of birth asphyxia is highly associated with intimate partner violence during pregnancy. This finding emphasizes the critical need in providing IPV screening during pregnancy and the importance of providing much needed counseling and preventative services to women. This is something that calls for collaboration between academic medical institutions like Mekelle University's College of Health Sciences, the Federal Minister of Health of Ethiopia and Tigray Regional Health Bureau. Community awareness should include men and community leaders who can play a significant role in reducing IPV during pregnancy. Organizations working to restore gender equity should align their missions with health care workers with one of their goals being reducing IPV during pregnancy.

\section{List Of Abbreviations}


IPV: intimate partner violence, PROM: premature rapture of membrane, ANC: antenatal care, EDHS: Ethiopia demographic health survey, COD: crude odds ratio, AOR: adjusted odds ratio.

\section{Declarations}

\section{Ethics approval and consent to participate}

An ethical approval for the study was obtained from Mekelle University College of Health Sciences Health Research Ethics Review Committee with the project registration number (ERC1364/2018). The study subjects provided written consent to participate in the study after receiving information about the purpose of the study, risks and benefits, and their rights. For participants who under age written consent was obtained from their parents.

\section{Consent for publication}

Not applicable

\section{Availability of data and materials}

The data used in this study are available with the corresponding author and possible to share upon reasonable request.

\section{Competing interest}

The authors declare that they have no competing interest.

\section{Funding}

Mekelle University helped financially in conducting this research but has no role in design, data collection, interpretation, analysis and writing of the manuscript.

\section{Author Contributions}

$\mathrm{KG}$ is participated in design proposal, monitoring during data collection, analysis and manuscript writing. $\mathrm{GG}, \mathrm{DZ}, \mathrm{SW}, \mathrm{MM}, \mathrm{AB}$ and $\mathrm{RN}$ also participated in reviewing the proposal, monitoring during data collection, analysis and review of the manuscript. All the authors have read and approved the manuscript.

\section{Authors' information's}

KG, SW, MM, DZ, AB and GG Mekelle University College of Health Sciences,

RN Oregon Health\& Science University; Kaiser Permanente Northwest

\section{References}


1. World Health Organization \& Pan American Health Organization. (2012). Understanding and addressing violence against women : intimate partner violence. World Health Organization. https://apps.who.int/iris/handle/10665/77432

2. World Health Organization, Dept. of Reproductive Health and Research, Intimate partner violence during pregnancy Information sheet, Number of pages: 4 Publication date: 2011.

3. Garcia-Moreno C, Jansen HA, Ellsberg M HL, CH W. Domestic Violence against Women Study Team. Prevalence of intimate partner violence: findings from the WHO multi-country study women's health and domestic violence. Lancet. 2006;368:1260-9.

4. Karen M Devries, Sunita Kishor, Holly Johnson, Heidi Stöckl, Loraine J Bacchus, Claudia GarciaMoreno \& Charlotte Watts, Intimate partner violence during pregnancy: analysis of prevalence data from 19 countries, Reproductive Health Matters 2010;18(36):158-170.

5. Shamu S, Abrahams N, Temmerman M M, A ZC. Systematic Review of African Studies on Intimate Partner Violence against pregnant Women: Prevalence and Risk Factors. PLoS One. 2011;6(3):e17591.

6. Casey $\mathrm{BM}^{1}$, McIntire DD, Leveno KJ. the continuing value of the apgar score for the assessment of newborn infants. N Engl J Med. 2001 Feb 15;344(7):467-71.

7. Paul VK, Deorari AK. Original Articles Correlates of mortality among hospital-born neonates with birth asphyxia. 1997;10(2):54-7.

8. WHO, Neonatal and Perinatal Mortality Country, Regional and Global Estimates, 2006.

9. Harrington DJ, Redman CW, Moulden M, Greenwood CE. The long-term outcome in surviving infants with Apgar zero at 10 minutes : a systematic review of the literature and hospital-based cohort. 2007; (May):1-5.

10. Salustiano EM ${ }^{1}$, Campos JA, Ibidi SM, Ruano R, Zugaib M., Low Apgar scores at 5 minutes in a low risk population: maternal and obstetrical factors and postnatal outcome, Rev Assoc Med Bras (1992). 2012 Sep-Oct;58(5):587-93.

11. Margaret H. Kearney Lois A. Haggerty Barbara H. Munro Joellen W. Hawkins, Birth Outcomes and Maternal Morbidity in Abused Pregnant Women With Public Versus Private Health Insurance, journal of nursing scholarship, 2003; 35:4, 345-349.

12. Laelago T, Belachew T, Tamrat M. Effect of intimate partner violence on birth outcomes . Afr Health Sci. 2017;17(3):681-9.

13. Survey H. Ethiopia. 2019.

14. Demelash H, Nigatu D, Gashaw K. A Case-Control Study on Intimate Partner Violence during Pregnancy and Low Birth Weight, Southeast Ethiopia. 2015;2015.

15. Gudayu TW. Proportion and factors associated with low fifth minute Apgar score among singleton newborn babies in Gondar University referral hospital; North West Ethiopia. Afr Health Sci. 2017;17(1):1-6. 
16. WHO, WHO multi-country study on women's health domestic violence against women, 2005. http://www.who.int/gender/violence/en/

17. Sigalla GN, Mushi D, Meyrowitsch DW, Manongi R, Rogathi JJ, Gammeltoft T, et al. Intimate partner violence during pregnancy and its association with preterm birth and low birth weight in Tanzania: A prospective cohort study. PLoS One. 2017;12(2):1-14

18. Hoang TN, Van TN, Gammeltoft T, Meyrowitsch DW, Thuy HNT, Rasch V. Association between intimate partner violence during pregnancy and adverse pregnancy outcomes in Vietnam: A prospective cohort study. PLoS One. 2016;11(9).

19. wayessa zelalem jebessa, Belachew T, Joseph J. Birth asphyxia and associated factors among newborns delivered in Jimma zone public hospitals, Southwest Ethiopia: A cross-sectional study. 2018;(5). Available from: http://eprints.mums.ac.ir/9675/

20. Ibrahim NA, Muhye A, Abdulie S. Prevalence of Birth Asphyxia and Associated Factors among Neonates Delivered in Dilchora Referral Hospital, in Dire Dawa, Eastern Ethiopia. Clin Mother Child Heal [Internet]. 2017;14(4).

21. Jeanne L. Alhusen, Phd, CRNP, RN, Ellen Ray, DNP, CNM, [...], And Linda Bullock, Phd, RN, Faan, Intimate Partner Violence During Pregnancy: Maternal and Neonatal Outcomes, j women health, 2015, 24(1).

22. Kovavisarach E1 JC. Risk factors of delivery of low apgar score newborn below 7 at 1 minute. J Med Assoc Thai.1999;82(7):660-5.

23. Rogers JF1 GW. Risk factors associated with low Apgar scores in a low income population. Pediatric Perinatal Epidemiology. 1993;7(2):205-16. 